\title{
PATENTWATCH
}

\section{Lipitor scope upheld but second patent invalid}

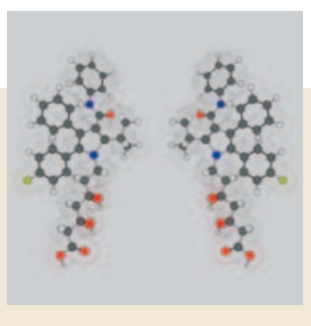

The scope of one of Pfizer's patents covering atorvastatin, the active ingredient in the company's blockbuster cholesterol-lowering drug Lipitor, has been upheld by a British Court, but the ruling that a second patent covering the calcium salt of the drug is invalid could shorten Pfizer's overall exclusivity.

The cases were brought by Indian pharmaceutical company Ranbaxy Laboratories and the UK firm Arrow Generics. Ranbaxy sought a declaration of non-infringement to enable it to sell atorvastatin upon expiry of one of Pfizer's patents (UK 0,247,633), and both companies attempted to revoke Pfizer's second atorvastatin patent (UK $0,409,281)$ on grounds of anticipation and obviousness.

The first case focused on the scope of the ' 633 patent and whether the description of atorvastatin describes each enantiomer of the drug (and by doing so claims the active single $R, R$ enantiomer) or whether it exclusively claims the racemate form (a 50\% mixture of both enantiomers). The judge felt that a person skilled in the art would know both that the racemate form contains the single active enantiomer and how to resolve the racemate to obtain this active ingredient, and ruled that the scope therefore covers the racemate and its constituent enantiomers.
The '281 patent, which covers a method for making a calcium salt of atorvastatin with improved pharmaceutical properties, was found to be anticipated and lacking in inventive step. A prior Pfizer patent application (WO 89/07598) claims methods for making preferred enantiomers of atorvastatin, and discloses the pharmaceutical composition of the active ingredient by including an optional synthesis step. The judge also found that the '281 patent lacked inventive step on two counts: that the ' 633 patent teaches the possibility to make metal (including calcium) salts of atorvastatin, and that only after the priority date of the ' 281 patent did it become apparent that the calcium salt provided any benefits over the sodium salt. That is, rather than the calcium salt being 'invented' to improve pharmaceutical properties, it was an obvious next step for a skilled person in the art to reformulate the drug in this way.

Sales from a generic version of atorvastatin were estimated to net Ranbaxy US\$800 million. Both Pfizer and Ranbaxy will appeal the rulings, and Ranbaxy is also challenging Lipitor patents in the US later this year.

Joanna Owens 